\title{
A Deficiência Visual e a Baixa Visão: estado da arte das pesquisas acadêmicas em Educação Matemática
}

\section{Visual Impairment and Low Vision: state of the art of academic research in Mathematical Education}

\author{
Rosana Maria Mendes* \\ ORCID iD 0000-0002-9366-6703 \\ Adrielly Antonia Santos Gomes** \\ ORCID iD 0000-0001-7028-3788 \\ Silvia Maria Medeiros Caporale ${ }^{* * *}$ \\ ORCID iD 0000-0002-9051-013X
}

\begin{abstract}
Resumo
Este artigo, de caráter qualitativo e que se enquadra no grupo de pesquisas denominado "Estado da Arte", apresenta uma análise dos resultados obtidos a partir de uma investigação que teve como objetivo mapear os trabalhos acadêmicos que relacionam a Educação Matemática e a Educação Inclusiva. Os dados foram constituídos por meio de pesquisas em trabalhos acadêmicos (teses e dissertações) disponíveis no Catálogo de Teses e Dissertações da Coordenação de Aperfeiçoamento de Pessoal de Nível Superior (CAPES), nas áreas de avaliação de Educação, Ensino, Ensino de Ciências e Matemática, Interdisciplinar, Multidisciplinar, como também nos artigos disponíveis nas revistas de classificações A1, A2, B1, B2, B3, B4 e B5, a partir dos Qualis Periódicos da Plataforma Sucupira nas áreas de avaliação de Ensino e Educação. Por intermédio da metodologia de Análise de Conteúdo foram estabelecidas três categorias de análise que possibilitaram perceber como tem ocorrido a Inclusão de estudantes com deficiência visual em se tratando da Educação Matemática Inclusiva, os aspectos relacionados à prática docente no processo de ensinar Matemática e as potencialidades dos recursos didáticos na aprendizagem Matemática de estudantes cegos ou com baixa visão.
\end{abstract}

Palavras-chave: Cegos. Baixa Visão. Educação Matemática Inclusiva. Pesquisa Bibliográfica.

\begin{abstract}
This qualitative article that fits in the research group called "State of Art" presents an analysis of the results obtained from a research aimed at mapping the academic works related to Mathematical Education and Inclusive Education. The data were constituted by research of academic works (theses and dissertations), available in the Catalog of Theses and Dissertations of the Catálogo de Teses e Dissertações da Coordenação de Aperfeiçoamento de Pessoal de Nível Superior (CAPES), in the area of Interdisciplinary Education, Teaching, Science, and Mathematics Evaluation, Multidisciplinary, as well as articles available in journals of classifications A1, A2, B1,

\footnotetext{
* Doutora em Educação Matemática pela Universidade Estadual Paulista "Júlio de Mesquita Filho" (UNESP campus Rio Claro). Professora Adjunta IV na Universidade Federal de Lavras (UFLA), Lavras, Minas Gerais, Brasil. E-mail: rosanamendes@ufla.br.

** Mestranda em Ensino de Ciências e Educação Matemática pela Universidade Federal de Lavras (UFLA). Atualmente é professora em uma Instituição Privada de ensino básico, Bom Sucesso, Minas Gerais, Brasil. Email: adrielly.gomes@estudante.ufla.br.

*** Doutora em Educação pela Universidade São Francisco (USF). Professora Adjunta IV na Universidade Federal de Lavras (UFLA), Lavras, Minas Gerais, Brasil. E-mail: silviacaporale@ufla.br.
} 
B2, B3, B4 and B5 from Qualis Periodicals of the Sucupira Platform in the areas of Assessment, Teaching, and Education. Through Content Analysis, three analysis categories were established making it possible to understand how the inclusion of students with visual impairment in Inclusive Mathematical Education has occurred, aspects related to teaching practice in the process of teaching mathematics and the potentialities of didactic resources in learning mathematics for blind or low vision students.

Keywords: Blind. Low vision. Inclusive Mathematical Education. Bibliographic research.

\section{Introdução}

Desde a década de 1990, políticas envolvendo as pessoas com deficiência vêm sendo reformuladas para assegurar a essas pessoas uma Educação de qualidade. A partir da Declaração de Salamanca ${ }^{1}$, podemos perceber os traços da Inclusão Escolar surgindo e reforçando o direito para todos ao acesso à Educação. A partir de então, fica evidente a necessidade de realizar uma revisão bibliográfica para entender o que vem sendo pesquisado e, não somente isso, mas também contribuir com o surgimento de novas pesquisas na área da Educação Inclusiva.

Para tanto, realizamos uma pesquisa de caráter qualitativo do tipo "Estado da Arte", em que mapeamos não só os trabalhos acadêmicos (teses e dissertações) disponíveis no Catálogo de Teses e Dissertações da Coordenação de Aperfeiçoamento de Pessoal de Nível Superior (CAPES), nas seguintes áreas de avaliação: Educação, Ensino, Ensino de Ciências e Matemática, Interdisciplinar, Multidisciplinar, mas também os artigos científicos disponíveis nos Qualis Periódicos da Plataforma Sucupira, nas áreas de avaliação de Ensino e Educação, publicados nas revistas de classificações A1, A2, B1, B2, B3, B4 e B5².

Por meio dessa investigação, buscamos responder o seguinte questionamento: $o$ que apontam os trabalhos acadêmicos sobre o processo de ensino e de aprendizagem de Matemática aos estudantes cegos ou com baixa visão?

Desta forma, nosso intuito é perceber as particularidades envolvendo o processo de ensino e de aprendizagem de estudantes cegos ou com baixa visão apresentadas nos trabalhos acadêmicos, de maneira a contribuir com a Literatura sobre o tema e alcançar nosso objetivo que é fazer um mapeamento dos trabalhos acadêmicos que relacionam a Educação Matemática e a Educação Inclusiva.

\footnotetext{
${ }^{1}$ Declaração de Salamanca. Disponível em: http://portal.mec.gov.br/seesp/arquivos/pdf/salamanca.pdf. Acesso em: 23 dez. 2019.

2 O documento com todos os resumos dos trabalhos encontrados está disponível em https://drive.google.com/file/d/1CdHTTLUUUVcxrxvVYz5jC6wHfVkO6zbG/view?usp=sharing. Acesso em: mai. 2020 .
} 


\section{Caminho para a constituição dos dados}

Nessa seção, apresentamos os procedimentos metodológicos utilizados para a constituição dos dados mediante a pesquisa realizada nas teses, nas dissertações e nos artigos científicos sobre o tema objeto da nossa análise.

\subsection{Teses e dissertações}

A princípio, realizamos um mapeamento dos trabalhos que relacionavam a Educação Matemática e a Educação Inclusiva, cujas investigações visavam especificamente a deficiência visual e a baixa visão, disponíveis no Catálogo de Teses e Dissertações da Coordenação de Aperfeiçoamento de Pessoal de Nível Superior (CAPES). A constituição dos dados aconteceu no período de 14/11/2017 à 07/04/2020, por meio da utilização dos seguintes descritores: Cego; Cega; Cegos; Cegueira; Deficiência Visual; Deficiente Visual; e Baixa Visão, os quais possibilitaram maior abrangência dos trabalhos encontrados. Para refinarmos as buscas, selecionamos a área de avaliação de Ensino, Educação, Interdisciplinar, Multidisciplinar e Ensino de Ciências e Matemática.

Ao final, localizamos os trabalhos em formato digital e obtivemos o total de 107 (cento e sete) pesquisas, distribuídas conforme consta na Tabela 1:

Tabela 1 - Relação de pesquisas do Mestrado, do Mestrado Profissional e do Doutorado, sobre Educação Matemática Inclusiva

\begin{tabular}{ccc}
\hline Nível & Quantidade & Porcentagem \\
\hline Mestrado & 46 & $43,00 \%$ \\
Mestrado Profissional & 39 & $36,44 \%$ \\
Doutorado & 22 & $20,56 \%$ \\
\hline Total & $\mathbf{1 0 7}$ & $\mathbf{1 0 0 , 0 0 \%}$ \\
\hline
\end{tabular}

Fonte: Das autoras (2020)

Em seguida, iniciamos o preenchimento das fichas de análises com os dados que seriam suficientes para abranger as informações necessárias para a investigação que seria realizada, conforme quadro a seguir (Quadro1):

\begin{tabular}{|l|l|}
\hline Título: & Autor: \\
\hline Nível: & Curso: \\
\hline Instituição: & Ano da defesa: \\
\hline Orientador/Orientadora: & \\
\hline Resumo: & Tipo de pesquisa: \\
\hline Palavras-chaves: & Objetivo (s) específico (s) da pesquisa: \\
\hline Questão de investigação: & Local: \\
\hline Objetivo (s) geral (is) da pesquisa: & \\
\hline Sujeitos: & Instrumento de constituição de dados: \\
\hline Materiais utilizados:
\end{tabular}


Conteúdos matemáticos discutidos:

Considerações finais:

Referências bibliográficas:

Quadro 1 - Ficha de Análise dos trabalhos

Fonte: Das autoras (2020)

\subsection{Artigos científicos}

Os dados dos artigos científicos foram constituídos a partir da pesquisa feita nos Qualis Periódicos da Plataforma Sucupira nas áreas de avaliação de Ensino e Educação, buscando as revistas no evento de classificação de periódicos do quadriênio 2013-2016.

A constituição dos dados aconteceu no período de 29/08/2018 à 25/04/2020, essa última data está relacionada a um retorno às revistas para revisão das buscas realizadas. Realizamos o mapeamento dos artigos científicos encontrados nas revistas de classificações A1, A2, B1, B2, B3, B4 e B5 a partir dos seguintes descritores: Cegueira, Cegos e Baixa Visão. Encontramos 110 (cento e dez) artigos que relacionavam a Educação Matemática e a Educação Inclusiva e que se relacionavam com nosso objetivo de pesquisa.

\subsection{Exploração do material}

Para a análise dos dados, utilizamos a metodologia proposta por Mendes e Miskulin (2017), denominada Análise de Conteúdo. Então, iniciamos a exploração do material elencando os temas, ou seja, estabelecemos a unidade de registro que "é a menor parte do conteúdo, cuja ocorrência é registrada de acordo com as categorias levantadas" (FRANCO, 2008, p. 41).

Desta forma, por meio da pesquisa feita nos trabalhos acadêmicos, estabelecemos 78 temas. Posteriormente, ao percebermos a relação entre os temas, estabelecemos 10 unidades de contexto, que chamamos de Eixos temáticos (Quadro 2):

\begin{tabular}{|l|l|}
\hline \multicolumn{1}{|c|}{ Eixos Temáticos } & \multicolumn{1}{|c|}{ Temas Iniciais } \\
\hline Prática Pedagógica & $\begin{array}{l}\text { Adequar o tempo mediante a atividade do estudante; Experiência do } \\
\text { docente em atuar com estudantes com deficiência visual; Explicação oral }\end{array}$ \\
& $\begin{array}{l}\text { do conteúdo realizado pelo docente; Mediação do professor; } \\
\text { Metodologia; Prática docente; Simplificação de conteúdo; Tratamento } \\
\text { desigual do docente em relação aos estudantes cegos; Ensino de }\end{array}$ \\
& $\begin{array}{l}\text { Matemática; Conteúdo matemático; Relação conteúdo-realidade; } \\
\text { Acessibilidade aos conceitos matemáticos; Avaliação do estudante }\end{array}$ \\
\hline Cargos docentes & Professor Brailista; Professor da sala de recurso; Professor de Apoio. \\
\hline Conhecimento docente & $\begin{array}{l}\text { Análise de recursos didáticos; Conhecimento do conteúdo para } \\
\text { adaptação; Conhecimento docente do material pedagógico; Docente tem } \\
\text { de conhecer seus estudantes; Apropriação do conhecimento por parte do }\end{array}$ \\
\hline Estudante no processo de & $\begin{array}{l}\text { Apropriação do conhecimento por parte do estudante; Compreensão do } \\
\text { aprendizagem }\end{array}$ \\
& estudante; Conhecimento do estudante; Dificuldades do estudante; \\
& Estratégias dos estudantes cegos ou com baixa visão; Estudantes com \\
\hline
\end{tabular}




\begin{tabular}{|l|l|}
\hline & $\begin{array}{l}\text { deficiência visual consideram ser difícil aprender Matemática; } \\
\text { Participação ativa dos estudantes; Realização de atividades matemáticas; } \\
\text { Representações gráficas; Resolução de problemas; Desempenho do } \\
\text { estudante em Matemática; Estudantes cegos tem a capacidade de } \\
\text { aprender; Memorização de conceitos; Aprendizagem de conceitos; } \\
\text { Construção de ideias; Limitações sensoriais. }\end{array}$ \\
\hline Orientação Familiar & Família no processo de escolarização; Orientação familiar. \\
\hline Formação docente & $\begin{array}{l}\text { Falta de qualificação docente; Formação continuada; Formação } \\
\text { docente; Professor(a) com formação recente; Saberes docente; } \\
\text { Aprendizagem da docência; Capacitação dos professores; Dificuldades } \\
\text { do docente }\end{array}$ \\
\hline Inclusão & $\begin{array}{l}\text { Integração; Leis e decretos; Inclusão escolar; Educação inclusiva; Sala } \\
\text { de recurso; Acessibilidade; Dificuldade da escola; Adaptação } \\
\text { curricular; Atendimento Educacional Especializado (AEE); Condições } \\
\text { do ambiente escolar }\end{array}$ \\
\hline Interação dos estudantes & $\begin{array}{l}\text { Apoio de uma pessoa vidente; Autonomia do discente; Compensação; } \\
\text { Desenvolvimento cognitivo; Dialogia; Interação dos estudantes; } \\
\text { Pessoas cegas têm a mesma percepção de uma pessoa vidente; Relações } \\
\text { sociais; Sentidos remanescentes; Visualidade }\end{array}$ \\
\hline Pesquisas em Educação & $\begin{array}{l}\text { Educação Matemática; Memorial de formação; Narrativas; Revisão } \\
\text { bibliográfica }\end{array}$ \\
\hline Matemática Inclusiva & $\begin{array}{l}\text { Análise do material por parte do estudante de Materiais; Material } \\
\text { didático criado ou adaptado; Mediação do material; Recursos } \\
\text { tecnológicos; Sistema Braille; Materiais manipulativos; Orientação e } \\
\text { mobilidade }\end{array}$ \\
\hline
\end{tabular}

Quadro 2 - Ficha de Análise dos trabalhos Fonte: Das autoras (2020)

Em seguida, realizamos a categorização dos dados respeitando os princípios propostos por Mendes e Miskulin (2017), sendo esses: exclusão mútua, homogeneidade, pertinência, objetividade e fidelidade, produtividade.

No Quadro 3 apresentamos as categorias de análise definidas a partir das teses, dissertações e dos artigos científicos.

\begin{tabular}{|l|ll|}
\hline \multicolumn{1}{|c|}{ Categorias de Análise } & \multicolumn{1}{|c|}{ Eixo temático } \\
\hline $\begin{array}{l}\text { A Educação Matemática Inclusiva na } \\
\text { perspectiva da Deficiência Visual }\end{array}$ & $\begin{array}{l}\text { Inclusão; Orientação familiar; Pesquisas em Educação } \\
\text { Matemática Inclusiva }\end{array}$ \\
\hline $\begin{array}{l}\text { Aspectos da prática docente no processo } \\
\text { de ensinar Matemática }\end{array}$ & $\begin{array}{l}\text { Formação docente; Prática pedagógica; Cargos docentes; } \\
\text { Conhecimento docente. }\end{array}$ \\
\hline $\begin{array}{l}\text { As potencialidades dos materiais } \\
\text { concretos para a aprendizagem } \\
\text { matemática de estudantes cegos ou com } \\
\text { baixa visão }\end{array}$ & $\begin{array}{l}\text { Recursos didáticos; Estudante no processo de aprendizagem; } \\
\text { Interação dos estudantes. }\end{array}$ \\
\hline
\end{tabular}

Quadro 3 - Categorias de Análise a partir dos trabalhos acadêmicos

Fonte: Das autoras (2020)

\section{0 que os trabalhos acadêmicos evidenciam?}

Nessa seção, apresentamos as produções das teses e dissertações que relacionam a Educação Matemática e a Educação Inclusiva no âmbito brasileiro e a relação das revistas encontradas de acordo com as suas classificações. Além disso, mostramos os conteúdos matemáticos que vêm sendo desenvolvidos no processo de ensino e de aprendizagem de 
estudantes cegos ou com baixa visão.

\subsection{Produções das teses e dissertações nos estados do Brasil}

Apresentamos, a seguir, as produções de teses e dissertações nos estados do Brasil e as instituições de ensino em que foram desenvolvidos os trabalhos (Tabela 2).

Tabela 2 - Publicações das teses e dissertações nos estados brasileiros

\begin{tabular}{|c|c|c|c|c|c|c|}
\hline Regiões & Estados & Instituições & Doutorado & Mestrado & $\begin{array}{c}\text { Mestrado } \\
\text { Profissional }\end{array}$ & Total \\
\hline \multirow[t]{23}{*}{ Sudeste } & São Paulo & UNIBAN & & 4 & & 4 \\
\hline & & PUC/SP & 4 & 1 & 1 & 6 \\
\hline & & UNESP & 2 & 8 & & 9 \\
\hline & & MACKEZINE & & 1 & & 1 \\
\hline & & MOURA & & 1 & & 1 \\
\hline & & LACERDA & & & & \\
\hline & & UNIAN & 3 & 1 & & 4 \\
\hline & & UFSCar & 1 & 1 & 1 & 3 \\
\hline & & UFAB & & 1 & & 1 \\
\hline & Minas Gerais & UFOP & & 1 & 2 & 3 \\
\hline & & PUC Minas & & & 2 & 2 \\
\hline & & UFJF & & & 1 & 1 \\
\hline & $\begin{array}{l}\text { Espírito } \\
\text { Santo }\end{array}$ & UFES & & & 1 & 1 \\
\hline & & FVC & & & 1 & 1 \\
\hline & & IFES & & & 1 & 1 \\
\hline & $\begin{array}{l}\text { Rio de } \\
\text { Janeiro }\end{array}$ & $\begin{array}{c}\text { UNIGRANRI } \\
\mathrm{O}\end{array}$ & & & 2 & 2 \\
\hline & & UFF & & & 2 & 2 \\
\hline & & $\begin{array}{c}\text { Colégio Pedro } \\
\text { II }\end{array}$ & & & 1 & 1 \\
\hline & & Universidade & & & 1 & 1 \\
\hline & & Severino & & & & \\
\hline & & Sombra & & & & \\
\hline & & UFRJ & & 1 & & 1 \\
\hline & & UENF & & & 3 & \\
\hline Total & & & 10 & 20 & 19 & 49 \\
\hline \multirow{14}{*}{ Sul } & Paraná & UTFPR & & & 1 & 1 \\
\hline & & UFPR & & & 3 & 3 \\
\hline & & Unicentro & & & 1 & 1 \\
\hline & $\begin{array}{c}\text { Rio Grande } \\
\text { do Sul }\end{array}$ & UFMS & & 1 & & 1 \\
\hline & Santa & ULBRA & & 3 & & 3 \\
\hline & Catarina & & & & & \\
\hline & & UFRGS & 2 & & 1 & 3 \\
\hline & & PUCRS & & 2 & & 2 \\
\hline & & UNIFRA & & & 1 & 1 \\
\hline & & PUCRS & 1 & & & 1 \\
\hline & & UNIVATES & & & 1 & 1 \\
\hline & & UDESC & & & 2 & 2 \\
\hline & & UFSC & & 2 & & 2 \\
\hline & & FURB & 1 & & 1 & 2 \\
\hline Total & & & 4 & 8 & 11 & 23 \\
\hline
\end{tabular}




\begin{tabular}{|c|c|c|c|c|c|c|}
\hline \multirow[t]{9}{*}{ Nordeste } & Sergipe & UFS & & 4 & & 4 \\
\hline & Alagoas & UFAL & & & 1 & 1 \\
\hline & Bahia & UESC & & 2 & & 2 \\
\hline & & UEFS & & 3 & & 3 \\
\hline & Ceará & UFC & 2 & 2 & & 4 \\
\hline & Paraíba & UEPB & & & 2 & 2 \\
\hline & & UTFPR & & & 1 & 1 \\
\hline & Pernambuco & UFPE & 1 & 1 & & 2 \\
\hline & Maranhão & UFMA & & & 1 & 1 \\
\hline Total & & & 3 & 12 & 5 & 20 \\
\hline \multirow[t]{5}{*}{$\begin{array}{c}\text { Centro- } \\
\text { Oeste }\end{array}$} & $\begin{array}{l}\text { Distrito } \\
\text { Federal }\end{array}$ & FE/Unb & & 1 & & 1 \\
\hline & Mato Grosso & UFMT & 1 & & & 1 \\
\hline & & UFMS & & 1 & & 1 \\
\hline & Goiás & UFG & & & 2 & 2 \\
\hline & & UEG & & & 1 & 1 \\
\hline Total & & & 1 & 2 & 3 & 6 \\
\hline \multirow[t]{6}{*}{ Norte } & Pará & UFPA & & 3 & & 3 \\
\hline & & REAMEC & 2 & & & 2 \\
\hline & Acre & REAMEC & 1 & & & 1 \\
\hline & & UFAC & & & 1 & 1 \\
\hline & Manaus & REAMEC & 1 & & & 1 \\
\hline & Tocantins & UFT & & 1 & & 1 \\
\hline Total & & & 4 & 4 & 1 & 9 \\
\hline Total Geral & & & 22 & 46 & 39 & 107 \\
\hline
\end{tabular}

Fonte: Das autoras (2020)

Podemos perceber que nos quatro estados da região sudeste encontra-se distribuído o maior número de produções acadêmicas que têm como tema a Educação Matemática Inclusiva de estudantes com deficiência visual. Já na região Centro Oeste, encontramos a menor produção desses trabalhos.

\subsection{Relação das revistas}

Na tabela 3, apresentamos não só a relação das revistas nas quais encontramos artigos científicos que versam sobre o processo de ensino e de aprendizagem de estudantes cegos ou com baixa visão, como também listamos a classificação de cada uma dessas revista.

Tabela 3 - Relação das Revistas

\begin{tabular}{|c|c|c|c|c|c|}
\hline Revistas & Instituições & $\begin{array}{c}\text { Educação } \\
\text { (Qualis) }\end{array}$ & $\begin{array}{c}\text { Ensino } \\
\text { (Qualis) }\end{array}$ & Quantidade & $\%$ \\
\hline Benjamin Constant (on-line) & IBC & B4 & B1 & 18 & $16,36 \%$ \\
\hline Educação Matemática em Revista & $\begin{array}{l}\text { UnB/ } \\
\text { SBEM }\end{array}$ & B1 & A2 & 13 & $11,82 \%$ \\
\hline Perspectiva da Educação Matemática & UFMS & B3 & B1 & 5 & $4,55 \%$ \\
\hline $\begin{array}{l}\text { Revista Paranaense de Educação } \\
\text { Matemática }\end{array}$ & UNESPAR & B5 & B1 & 5 & $4,55 \%$ \\
\hline $\begin{array}{l}\text { Rede Amazônica de Educação em } \\
\text { Ciências e Matemática }\end{array}$ & UFMT & $\mathrm{C}$ & B3 & 5 & $4,55 \%$ \\
\hline $\begin{array}{l}\text { Boletim Online de Educação } \\
\text { Matemática }\end{array}$ & UDESC & B4 & B1 & 4 & $3,64 \%$ \\
\hline $\begin{array}{l}\text { Renote - Revista Novas Tecnologias na } \\
\text { Escola }\end{array}$ & UFRGS & B2 & B1 & 4 & $3,64 \%$ \\
\hline
\end{tabular}




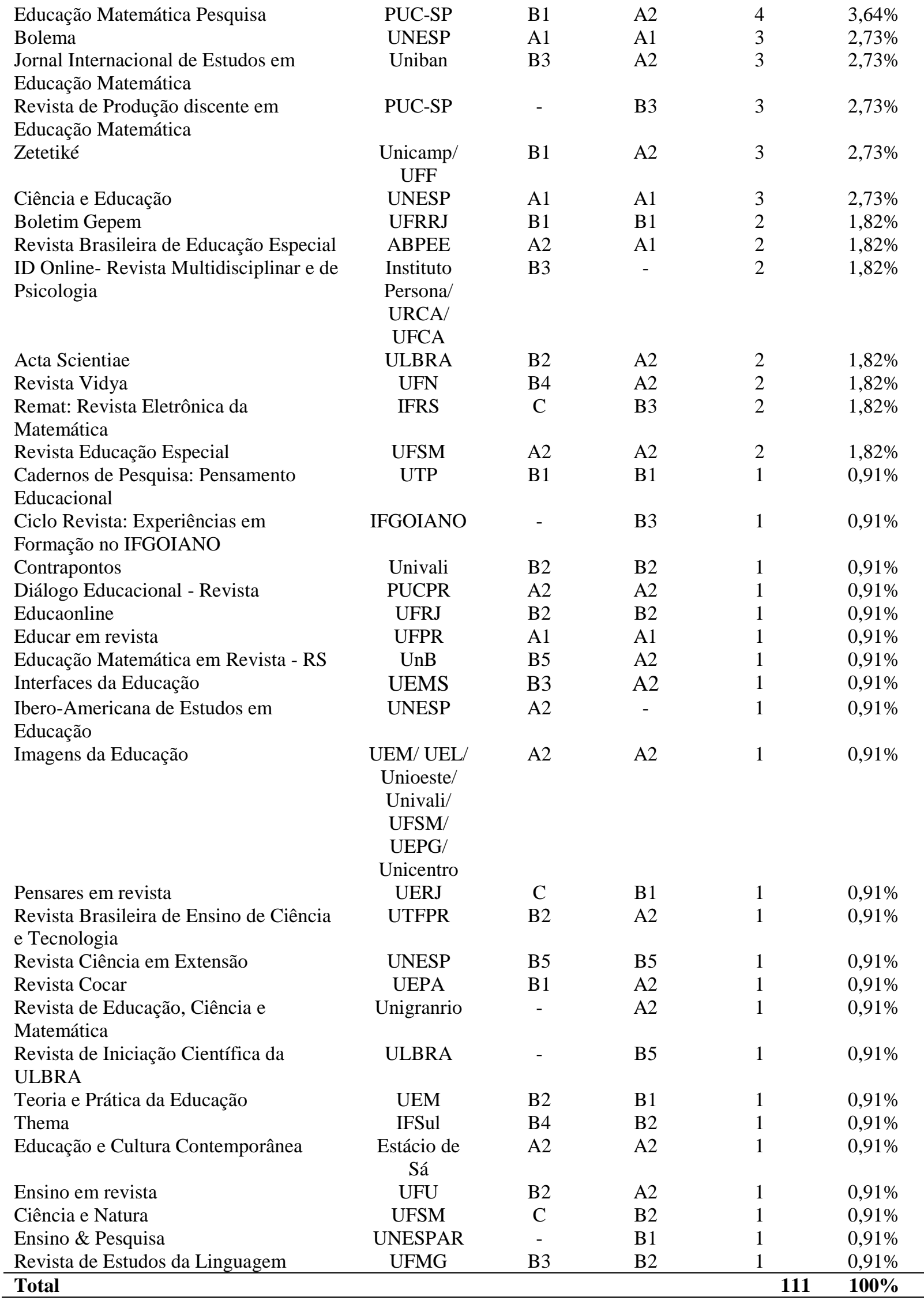




\subsection{Referências bibliográficas utilizadas nos trabalhos}

Fizemos, também, um levantamento das referências bibliográficas relacionadas nos trabalhos que tratavam da Educação Especial e/ou Educação Inclusiva. Verificamos que em praticamente todos esses trabalhos havia a menção à legislação pertinente, tais como leis, decretos, portarias e resoluções.

Apresentamos, no Quadro 4, as referências teóricas mais citadas ${ }^{3}$ que subsidiaram o estudo sobre a Educação Especial na perspectiva da Educação Inclusiva. A contagem foi realizada considerando a primeira autora ou primeiro autor. Muitos trabalhos apresentavam várias edições e optamos por trazer a referência mais recente.

\begin{tabular}{|c|c|}
\hline Referência & Quantidade \\
\hline Amiralian $(2010,2009,2007,2004,2000,1997,1992)$ & 20 \\
\hline $\begin{array}{l}\text { Bersch, Machado (2014); Bersch, Sartoretto (2012); Bersch }(2009,2008,2006) \text {; Bersch, Tonolli } \\
\text { (2007); Bersch, Machado (2007) }\end{array}$ & 22 \\
\hline $\begin{array}{l}\text { Borges (2009, 2004, 2003b, 2002a, 2002b); Borges, Barbosa, Jansen, Lyrio (2008); Borges, } \\
\text { Jensen (2002); Borges, Chagas Junior (2001) }\end{array}$ & 21 \\
\hline $\begin{array}{l}\text { Brandão }(2016,2014,2013 a, 2013 b, 2010,2009 a, 2009 b, 2008 a, 2008 b, 2008 c, 2007 a, 2007 b \text {, } \\
2006,2004,2003,2002)\end{array}$ & 40 \\
\hline $\begin{array}{l}\text { Bruno (2008); Bruno (2006); Bruno (2003); Bruno (2001a); Bruno (2001b); Bruno (2001c); } \\
\text { Bruno (2001d); Bruno (1999); Bruno (1997); Bruno (1992); }\end{array}$ & 26 \\
\hline Caiado (2014a, 2014b, 2009) & 25 \\
\hline $\begin{array}{l}\text { Camargo (2017, 2016, 2012, 2010, 2008, 2005); Camargo, Nardi, Anjos (2010); Camargo, Nardi } \\
\text { (2010); Camargo, Lippe (2009); Camargo, Nardi (2008a); Camargo, Nardi (2008b); Camargo, } \\
\text { Nardi, Veraszto (2008); Camargo, Silva, Barros Filho (2006); Camargo, Nardi (2006); Camargo, } \\
\text { Silva (2003a); Camargo, Silva (2003b); Camargo, Scalvi, Braga (2001) }\end{array}$ & 26 \\
\hline Cerqueira (2009a); Cerqueira (2009b); Cerqueira, Ferreira (2000) & 29 \\
\hline $\begin{array}{l}\text { Fernandes, Healy (2016a, 2016b, 2015, 2013, 2010, 2009a, 2009b, 2008, 2007a, 2007b, 2007c, } \\
\text { 2006a, 2006b, 2005, 2004a, 2004b, 2004c, 2004d, 2003); Fernandes, Healy, Serino (2014); } \\
\text { Fernandes, Healy, Frant (2013); Fernandes, Healy, Serino (2012); Fernandes et. al. (2011); } \\
\text { Fernandes (2011); Fernandes (2008) }\end{array}$ & 187 \\
\hline Ferronato (2002) & 45 \\
\hline Galvão Filho $(2013,2012 a, 2012 b, 2012 c, 2009 a, 2009 b, 2004,2002)$ & 24 \\
\hline Gil (2005); Gil (2000) & 25 \\
\hline $\begin{array}{l}\text { Healy, Nardi, Fernandes (2015); Healy, Santos (2014); Healy, Powell (2013); Healy, Fernandes } \\
\text { (2011a, 2011b); Healy, Ferronato, Souza (2007); Healy (2008, 2002); Healy, Sinclair (2007) }\end{array}$ & 23 \\
\hline $\begin{array}{l}\text { Kaleff, Rosa (2018, 2016, 2013, 2012, 2011); Kaleff (2016a, 2016b, 2012, 2010); Kaleff, Rosa, } \\
\text { Oliveira, Mourão (2013); Kaleff, Rosa, Telles (2013); Kaleff, Rosa, Votto (2010) }\end{array}$ & 35 \\
\hline $\begin{array}{l}\text { Mantoan (2013, 2007a, 2007b, 2005a, 2005b, 2005c, 2003a, 2003b, 2003c, 2002a, 2002b, 2002c, } \\
\text { 2001a, 2001b, 1998, 1997a, 1997b, 1989); Mantoan, Pantoja, Fávero (2007); Mantoan, Prietro } \\
\text { (2006) }\end{array}$ & 81 \\
\hline Marcelly (2015); Marcelly (2011); Marcelly (2010) & 29 \\
\hline Masini $(2011,2007 a, 2007 b, 2003,2002,1993,1984)$ & 20 \\
\hline Mazzotta (2011) & 28 \\
\hline $\begin{array}{l}\text { Mendes }(2016,2015,2014 a, 2014 b, 2012,2011 a, 2011 b, 2010 a, 2010 b,(2010 c, 2009,2007, \\
\text { 2006, 2004, 2002a, 2002b) }\end{array}$ & 23 \\
\hline Nunes $(2010,2008,2004)$ & 21 \\
\hline Ochaita $(2004,1995 a, 1995 b, 1993,1994)$ & 44 \\
\hline
\end{tabular}

3 A lista com as referências encontradas está disponível em: https://drive.google.com/file/d/1UaT88MF_PN_luL8TSqn-OiJCvDoUHSVG/view?usp=sharing. Acesso em: mai. 2020. 


\begin{tabular}{|l|c|}
\hline Reily $(2004)$ & 24 \\
\hline Sá $(2011,2010,2008,2007 a, 2007 b)$ & 52 \\
\hline Sassaki $(2010,2009,2007,2005,2003 a, 2003 b, 2002 a, 2002 b, 1998,1997)$ & 34 \\
\hline Uliana $(2018,2017,2016,2015,2014 a, 2014 b, 2013 a, 2013 b, 2012,2010)$ & 32 \\
\hline Vygotsky (1997) & 43 \\
\hline
\end{tabular}

Quadro 4 - Relação das referências bibliográficas utilizadas nas pesquisas

Fonte: Das autoras (2020)

No que se refere aos construtos teóricos, notamos uma multiplicidade de autores e autoras, a maioria nacionais. Nesse sentido, Solange Hassan Ahmad Ali Fernandes foi a autora mais citada (187 vezes); seus trabalhos tratam da Educação Matemática Inclusiva, sobretudo quando relacionada à deficiência visual. Ela figura em muitos trabalhos também como segunda ou terceira autora, principalmente em uma parceria significativa com Lulu Healy, que foi a estrangeira mais citada (23 vezes) como primeira autora. Foram encontradas algumas referências em inglês e espanhol, mantendo a pluralidade.

Além disso, notamos que Maria Teresa Eglér Mantoan foi a segunda autora brasileira mais citada (81 vezes); suas pesquisas discutem principalmente as temáticas da Educação Especial e Educação Inclusiva.

É interessante destacarmos, ainda, que a coletânea "Fundamentos de defectologia. Obras escogidas, Tomo V' (VYGOTSKY, 1997), foi a obra mais citada, com o objetivo de ressaltar o aspecto histórico-cultural da pesquisa com pessoas com deficiência.

\subsection{Conteúdos matemáticos apresentados nos trabalhos acadêmicos}

Após realizarmos o mapeamento dos trabalhos acadêmicos, percebemos a importância de compreender quais conteúdos matemáticos vêm sendo desenvolvidos no processo de ensino e de aprendizagem de estudantes cegos ou com baixa visão. Por tal motivo, apresentamos no Quadro 5 a relação desses conteúdos e dos recursos didáticos utilizados. A coluna "quantidade" se refere aos trabalhos que apresentavam os conteúdos matemáticos com a utilização de algum recurso didático, podendo estes estarem em diversas áreas do conhecimento, por abordarem mais de um conceito em seu desenvolvimento. 


\begin{tabular}{|c|c|c|}
\hline $\begin{array}{l}\text { Conteúdos } \\
\text { Matemáticos }\end{array}$ & Recursos Utilizados & Quantidade \\
\hline Geometria & $\begin{array}{l}\text { Blocos lógicos; Ferramentas; Figuras geométricas confeccionadas no papel } \\
\text { cartão; Tabuleiro de xadrez; Fichas coloridas; Reis; Tabuleiro com a face } \\
\text { graduada; Quadrados e retângulos graduados; Tabuleiro com a face sem } \\
\text { graduação; Quadrado e retângulos não graduados; Material Dourado; Dados; } \\
\text { Barbante; Trena; Histórias em Quadrinhos; Plano Cartesiano Adaptado; Eixos } \\
\text { Cartesiano Adaptado; Sólidos geométricos; Figuras geométricas de madeira; } \\
\text { Papel em relevo; Prancheta; Cartilha; Geoplano; Material manipulativo; } \\
\text { Recursos Tecnológicos; Multiplano; Varetas de Borracha; Material adaptado } \\
\text { em EVA; Transferidor adaptado; Embalagens de produtos do cotidiano; } \\
\text { Figuras geométricas recortadas em papelão para a construção de sólidos; } \\
\text { Massa de modelar; Régua adaptada; Figuras em EVA; Caixas de embalagens. } \\
\text { Quebra-Cabeça; Jogo da Velha; Sólidos de Acrílico; Soroban; Maquete; } \\
\text { Figuras Geométricas; Tecnologia Assistiva; Origami; Desenhos de figuras } \\
\text { planas utilizando elástico; Pipas; Material Confeccionado; Épura Tátil; } \\
\text { Objetos do dia a dia; Tangram; Régua com Medições em relevo; Polígonos } \\
\text { em EVA; Sistema Braille; Folhas com linhas em relevo; Cubos em 3D feitos } \\
\text { de Miriti; Dobradura; Ferramenta mediadora; Gestos como ferramenta } \\
\text { mediadora; Prancha; Placas de EVA; Sólidos com texturas; Placa metálica } \\
\text { com pontos em relevo; Bordados geométricos em relevo, Malha quadriculada } \\
\text { bordada em relevo; Videojogo "AudioGeometria"; Quadradinhos com } \\
\text { material dourado para confeccionar retângulos; descrição de textos; fita } \\
\text { métrica adaptada; Tangram estrelado; GeoGebra; Tapete de Sierpinski; } \\
\text { Ambiente virtual; Tangram pitagórico e malhas; Trena adaptada; Tricômetro } \\
\text { Plástico; Tricômetro Sucata; Polígonos em papel canson; Materiais concretos; } \\
\text { Lixa; Papel ofício; Kit pedagógico; Objetos escolares; Embalagens de } \\
\text { produtos; Material tátil - linhas poligonais e poliedros; Software Monet; } \\
\text { Material com papel do tipo paraná; Prancha modeladora; Cones de acetato; } \\
\text { Dobraduras e colagens; Tabuleiro de xadrez confeccionado. }\end{array}$ & 80 \\
\hline $\begin{array}{l}\text { Números } \\
\text { Operações }\end{array}$ & $\begin{array}{l}\text { Jogo do Resto; Multiplano; Soroban; Tangerinas; Material produzido; Célula } \\
\text { Braille; Reglete e punção; Máquina Braille; Código Braille; Adaptação das } \\
\text { Barras de Cuisenaire; Ábaco; Calculadora com sintetizador de voz; } \\
\text { Cubaritmo; Ambiente virtual; Objetos do dia a dia; Material adaptado; } \\
\text { Moedas; Caixa de operações; Material dourado; Tecnologia assistiva; } \\
\text { MusiCALcolorida; Recurso tecnológico; Cartas com algarismos; Quadro de } \\
\text { ordens; Caixa Sonora; Tabuleiro de decimais; Mancala; Ritmos; Jogo Fantan. }\end{array}$ & 37 \\
\hline Função & $\begin{array}{l}\text { Plotador sensorial; Tecnologia assistiva; Recursos tecnológicos; Não } \\
\text { especificado; Software Monet; Geoplano; Material em relevo; Atividades } \\
\text { lúdicas; Fichário para construção gráfica; Placa de Resolução de Equações do } \\
\text { Primeiro Grau; Malha quadriculada em relevo ou adaptada; Kit de material } \\
\text { pedagógico; Plano cartesiano de metal; Ferramenta adaptada; Atividades } \\
\text { lúdicas; Fichário para construção gráfica; EVA; Palitos; Recortes de papel; } \\
\text { Gráfico adaptado; Material confeccionado; Jogo das funções; Prancheta de } \\
\text { papelão com tela; Multiplano }\end{array}$ & 18 \\
\hline Probabilidade & Maquete tátil; Pictograma 3D; Baralho & 7 \\
\hline Fração & $\begin{array}{l}\text { Pão; Material adaptado; Folha de isopor; Quadro de metal; Goiabas; Lego; } \\
\text { Massa de modelar; Escala Cuisenaire; Brinquedo "monta fácil"; Bolinhas de } \\
\text { gude; Bolinhas de isopor; Círculo de frações adaptado; Origami; Material } \\
\text { manipulativo; Material composto por brinquedos; Peças dos círculos } \\
\text { fracionários }\end{array}$ & 10 \\
\hline Trigonometria & Material manipulativo; Geoplano; Material adaptado; Recursos didáticos & 4 \\
\hline $\begin{array}{l}\text { Matrizes e } \\
\text { Determinante }\end{array}$ & Matrizmat; Recursos tecnológicos & 4 \\
\hline Equações & $\begin{array}{l}\text { Material concreto; Malha quadriculada em relevo; Bolinhas de massinha de } \\
\text { modelar; Macarrão tipo espaguete; Não especificado }\end{array}$ & 4 \\
\hline $\begin{array}{l}\text { Análise } \\
\text { Combinatória }\end{array}$ & Materiais em EVA; Frutas; Caixa de ovos com bolinhas; Material concreto & 2 \\
\hline Estatística & Simulador de gráficos; Soroban; Cubaritmo; Software Monet; Material em & 4 \\
\hline
\end{tabular}




\begin{tabular}{|c|c|c|}
\hline & EVA & \\
\hline $\begin{array}{l}\text { Expressões } \\
\text { Numéricas }\end{array}$ & $\begin{array}{l}\text { Tabuleiro das expressões; Braille; Material Dourado; Material concreto; } \\
\text { Geoplano; Recursos tecnológicos }\end{array}$ & 3 \\
\hline $\begin{array}{l}\text { Cálculo } \\
\text { Diferencial ou } \\
\text { Integral } \\
\end{array}$ & $\begin{array}{l}\text { Recursos tecnológicos; Multiplano; Reglete e punção; Palitos para formar } \\
\text { triângulos; Ferramenta adaptada (caixa de fósforo); Fichas em alto-relevo }\end{array}$ & 4 \\
\hline $\begin{array}{l}\text { Coordenadas } \\
\text { Cartesiana }\end{array}$ & Gráfico adaptado; Batalha Naval adaptado & 2 \\
\hline Álgebra & Material manipulável tátil; Cubo mágico adaptado; Não especificado & 5 \\
\hline Potência & Lenda do xadrez; Tabuleiro de xadrez & 1 \\
\hline $\begin{array}{l}\text { Razão } \\
\text { Proporção }\end{array}$ & $\begin{array}{l}\text { Desenho da ferramenta tátil e sonora; Desenho do software Speech Table; } \\
\text { Desenho das tarefas }\end{array}$ & 1 \\
\hline $\begin{array}{l}\text { Matemática } \\
\text { Financeira }\end{array}$ & Tarefas Investigativas & 1 \\
\hline Sequências & Triângulos com palitos; Geoplano & 2 \\
\hline $\begin{array}{l}\text { Produtos } \\
\text { Notáveis }\end{array}$ & Kit Produtos Notáveis & 1 \\
\hline $\begin{array}{l}\text { Não } \\
\text { especificado }\end{array}$ & & 56 \\
\hline
\end{tabular}

Quadro 5 - Relação dos Conteúdos Matemáticos e dos Recursos didáticos

Fonte: Das autoras (2020)

A partir do Quadro 5, podemos constatar que as pesquisas acadêmicas abrangem diversas áreas do conhecimento matemático no processo de ensino e de aprendizagem de estudantes cegos ou com baixa visão. Desta forma, percebemos que os recursos didáticos possibilitaram aos estudantes a construção do conhecimento, como aponta Silva et al. (2019, p. 188),

Se os materiais didáticos manipuláveis podem trazer benefícios para a aprendizagem dos estudantes de um modo geral, eles se tornam essenciais para aquele que tem deficiência visual, principalmente o cego, cujo canal de ligação com o mundo não é a visão. Devido a ausência deste sentido é necessário que ele se apoie nos outros sentidos, sendo o tato um dos que melhor lhes possibilita a análise do meio em que vive

Algumas das pesquisas não especificaram o conteúdo abordado, estas apresentaram questões gerais acerca da Educação Matemática Inclusiva, tais como: o Atendimento Educacional Especializado, os desafios enfrentados pelos estudantes cegos no processo de escolarização, a formação do professor de Matemática, dentre outros.

\section{Análise dos trabalhos acadêmicos sobre o processo de ensino e de aprendizagem matemática de estudantes com deficiência visual}

Após a análise dos trabalhos acadêmicos, investigamos quais têm sido os avanços em relação à Educação Matemática Inclusiva de estudantes cegos ou com baixa visão. Desse modo, nessa seção, apresentamos algumas reflexões a partir das categorias levantadas com base na metodologia adotada, ou seja, a proposta de Mendes e Miskulin (2017), conforme mencionamos 
anteriormente.

\subsection{A Educação Matemática Inclusiva na perspectiva da Deficiência Visual}

A Educação Inclusiva, considerada em seu processo de desenvolvimento histórico, é importante para o processo de escolarização de estudantes com deficiência visual, pois, por meio dela, muitas barreiras se romperam ao longo do tempo, permitindo aos estudantes cegos ou com baixa visão acessibilidade tanto aos ambientes escolares, quanto aos conteúdos matemáticos.

Neste sentido, o advento da Educação Inclusiva implicou em mudanças na prática educativa de docentes, pois o modelo pedagógico agora se centra nos estudantes, com o intuito de dar respostas às necessidades educativas de cada um (BATISTA; MIRANDA; MOCROSKY, 2016). Segundo Landim, Maia e Sousa (2017, p. 68), a Educação Inclusiva "visa assegurar a todas as pessoas condições equitativas de aprendizagem, considerando que é papel da escola adequar-se às demandas e especificidades de todos os estudantes".

Em um ambiente inclusivo, entendemos que a orientação familiar dos estudantes com deficiência visual não só estimula seu desenvolvimento, como também se revela indispensável para o êxito das práticas nos contextos escolares, pois,

\footnotetext{
a segurança, confiança e a interação que estes alunos irão desenvolver em sala de aula é apenas uma continuidade do trabalho que já vinha sendo feito em casa com os pais e familiares. Esta participação também é solicitada durante a vida escolar do aluno e deve estar presente nas atividades escolares em geral (BATISTA; MIRANDA; MOCROSKY, 2016, p. 116).
}

Como continuidade deste ambiente inclusivo, conforme aponta Martins, Galiazzi e Lima (2017), há também o trabalho do Atendimento Educacional Especializado (AEE), que objetiva auxiliar os estudantes no processo de ensino e de aprendizagem de conteúdos trabalhados em sala de aula, por intermédio da disponibilização de recursos didáticos e tempos diferenciados para a realização de tarefas, de acordo com a necessidade de cada estudante. Os autores ainda complementam, destacando que "este atendimento não substitui as atividades desenvolvidas pelo professor regente da disciplina, como muitos docentes acreditam" (MARTINS; GALIAZZI; LIMA, 2017, p. 192).

Dessa maneira, a partir dos trabalhos analisados, percebemos que houve muitos avanços, porém muitas mudanças ainda precisam ser realizadas no contexto da Educação Matemática Inclusiva, com o rompimento de barreiras, como, por exemplo, as atitudinais, sendo essas, "atitudes ou comportamentos que impeçam ou prejudiquem a participação social da 
pessoa com deficiência em igualdade de condições e oportunidades com as demais pessoas" BRASIL (2015). Pois, assim, os estudantes com deficiência visual, através de algum tipo de comunicação que faça com que seja possível que eles participem das práticas desenvolvidas em sala de aula, continuarão a superar os desafios que lhes são impostos tanto no sentido educacional, quanto no social.

\subsection{Aspectos da formação e da prática docente no processo de ensinar Matemática}

A metodologia adotada pelo docente e suas práticas dentro de sala de aula influenciam diretamente na construção dos conceitos matemáticos dos estudantes cegos ou com baixa visão. Dessa forma, pudemos perceber a recorrência dos aspectos relacionados à formação e à prática docente nos trabalhos analisados, mostrando ser imprescindível atentar-se para tal fato.

Em se tratando da formação inicial docente, como destaca Viginheski et al. (2017), percebemos que esses profissionais enfrentam dificuldades quando se trata de ensinar conteúdos a estudantes com deficiência visual, fato que advém, na maioria das vezes, das carências apresentadas nos cursos de formação de professores.

Sobre o tema, entendemos que,

é importante e urgente discutir o que deve ser abordado nos cursos de formação de
professores para que os novos profissionais, ao entrarem na sala de aula e se
depararem com essa realidade, saibam como agir e não se guiem apenas pela intuição,
criando situações de tentativa e erro que podem prejudicar os alunos (MELLO, 2013,
p. 140)

Como aponta Viginheski et al. (2017), há a necessidade de o docente compreender os aspectos característicos da deficiência visual, além de entender como ocorre o desenvolvimento da aprendizagem dos estudantes com deficiência visual e quais recursos ele terá disponíveis para o ensino. Dessa forma, "o professor deve sempre buscar diversas alternativas de ensino para poder proporcionar aos seus alunos num ambiente propício ao acesso de informações e, consequentemente, ao desenvolvimento cognitivo" (PEREIRA, 2012, p. 143).

A utilização de materiais concretos no processo de ensino e de aprendizagem torna-se viável para a construção do conhecimento matemático. Assim, como destaca Brito (2007), o uso desses instrumentos propicia melhorias na aprendizagem de todos os educandos, sem exceção, pois atende às necessidades educacionais dos estudantes com deficiência visual.

Ao adotar estratégias de ensino que contribuem para que os estudantes cegos compreendam o conteúdo estudando, é essencial que o docente verbalize com clareza os conceitos, já que é indiscutível a relevância dos sentidos remanescentes para esses alunos 
durante o processo, inclusive a audição e a linguagem oral (BRITO, 2007).

Assim, no momento em que o docente cria recursos didáticos que vão possibilitar a construção do conhecimento Matemático de estudantes com deficiência visual, ele beneficia não só esses estudantes, mas também toda a classe, facilitando a compreensão do conceito trabalhado (FERRONATO, 2002). Neste sentido, entendemos que,

\begin{abstract}
São poucas as alternativas que os docentes têm para trabalhar conceitos matemáticos de forma concreta. Porém, a partir de estratégias simples criadas pelo próprio educador, os alunos podem ser estimulados a estarem buscando novas aprendizagens. São possibilidades que estão emergindo com maior intensidade nas últimas décadas, decorrentes principalmente da proposta inclusiva, que prima por salas heterogêneas o que, de certa forma, estimula o professor a estar buscando alternativas que possibilitem a aprendizagem de todos os alunos e não apenas de parte deles (FERRONATO, 2002, p. 49).
\end{abstract}

Desta maneira, entendemos as dificuldades enfrentadas pelos docentes no processo de ensinar Matemática a estudantes com deficiência visual, porém, sabemos que a sua prática docente, quando bem desenvolvida, propicia aos estudantes uma aprendizagem significativa. Assim, torna-se necessário que os docentes busquem compreender as particularidades da deficiência visual, pois "conhecer a diversidade é um passo importante para saber lidar com ela" (SANTOS; THIENGO, 2016, p. 105).

\title{
4.3 As potencialidades dos recursos didáticos para a aprendizagem Matemática de estudantes cegos ou com baixa visão
}

Ao analisarmos os trabalhos acadêmicos cujos dados foram empregados no presente estudo, percebemos que a utilização de recursos didáticos no processo de aprendizagem matemática por estudantes cegos ou com baixa visão mostrou-se fundamental para a compreensão dos conceitos desenvolvidos.

Os estudantes cegos utilizam os sentidos remanescentes para perceber o que acontece à sua volta. No meio educacional, podemos perceber que através desses outros sentidos os estudantes com deficiência visual captam as informações, as visualizam e as interpretam, o que possibilita a eles analisar as características de um ambiente ou de algum objeto, por exemplo (ULIANA, 2015).

Neste sentido, nas aulas de Matemática, "é necessária a utilização de material adaptado, que privilegie os sentidos remanescentes do estudante com cegueira" (FURLAN, 2016, p. 92). Pois, como aponta Neves e Maia (2018), para estudantes cegos ou com baixa visão, a adaptação do material se torna fundamental para o estudo de Matemática, uma vez que, por meio deles, os estudantes conseguem aprender os conteúdos matemáticos de forma segura, adquirindo 
autonomia nas atividades propostas pelo docente.

Os materiais concretos permitem que os estudantes com deficiência visual adquiram informações enriquecedoras aos seus conhecimentos, e não somente isso, já que o material também reduz as abstrações matemáticas que lhes são apresentadas (ULIANA, 2015).

Assim, no contexto da Matemática, torna-se fundamental a utilização de materiais manipulativos que possibilitam aos estudantes com deficiência visual a compreensão dos conceitos desenvolvidos, o que torna o "aluno integrante ativo nas atividades educacionais realizadas" (BATISTA; MIRANDA; MOCROSKY, 2016, p. 117).

Entendemos que os estudantes cegos ou com baixa visão criam estratégias para resolver problemas que aparecem em seus cotidianos, de modo que,

Para que esses alunos consigam desenvolver suas aptidões e se apropriarem dos
conceitos de maneira significativa, eles necessitam de um complemento, ou seja,
necessitam da utilização de materiais manipuláveis. A mediação no ensino da
matemática para alunos cegos requer contato direto com o que está sendo ensinado.
A utilização do material concreto vai permitir que o aluno literalmente "sinta" o que
está sendo ensinado e seja capaz de desenvolver suas abstrações compreendendo
assim, os conceitos matemáticos envolvidos (SPLETT, 2015, p. 93).

Dentre os materiais manipulativos e adaptados, como destaca Lirio (2006), os recursos tecnológicos têm se mostrado uma ferramenta educacional muito utilizada, tendo em vista que, por meio deles, os estudantes cegos ou com baixa visão têm acesso às informações que antes não eram acessíveis, o que faz com que esses recursos se tornem um facilitador no processo de ensino e de aprendizagem

Desta maneira, a utilização desses recursos permite que os conteúdos matemáticos desenvolvidos com os estudantes com deficiência visual sejam descritos com riqueza de detalhes durante a explicação, evitando não só a interpretação errônea do que se deseja que eles aprendam, mas também o uso das dêixis e distorções da "Matemática falada" (MIRANDA, 2016).

Mediante essas considerações acerca dos recursos didáticos, ficou evidente as potencialidades dessas ferramentas quando utilizadas adequadamente, pois contribuem durante o processo de construção de conhecimentos e de desenvolvimento cognitivo dos estudantes. Esses recursos também permitem aos estudantes maior acessibilidade aos conteúdos matemáticos, favorecendo a memorização dos conceitos trabalhados.

\section{Considerações finais}

A partir desse estudo, pudemos perceber vários fatores que estão relacionados ao 
processo de ensino e de aprendizagem de estudantes com deficiência visual. Neste sentido, realizamos um mapeamento dos trabalhos acadêmicos que vêm sendo desenvolvidos na perspectiva da Educação Matemática Inclusiva de estudantes cegos ou com baixa visão.

A partir da metodologia de "Análise de Conteúdo" proposta por Mendes e Miskulin (2017), chegamos às categorias de análise que nos permitiram refletir sobre o processo de Inclusão Escolar, os desafios enfrentados pelos docentes em sua prática e a potencialidade dos materiais manipulativos no processo de aprendizagem matemática.

Pudemos perceber que muitos foram os avanços no processo da inclusão escolar de estudantes com deficiência visual ao longo do tempo, mas que é preciso estar sempre repensando as melhorias que podem ser adotadas no âmbito educacional para que não haja nenhuma barreira durante o processo educacional desses estudantes.

Constatamos que a participação dos estudantes no AEE é fundamental, no que diz respeito à Educação Matemática Inclusiva, e que a presença da família no processo de escolarização propicia aos estudantes um desenvolvimento significativo.

Mesmo com as carências existentes nos cursos de formação inicial, percebemos a importância de os docentes estarem sempre em busca de novos conhecimentos acerca da deficiência visual e de novas alternativas de ensino que serão fundamentais no processo de construção dos conceitos matemáticos desenvolvidos.

Por fim, discutimos as potencialidades dos materiais concretos no processo de aprendizagem matemática, visto que os estudantes com deficiência visual utilizam dos sentidos remanescentes para captar as informações à sua volta. Dessa maneira, a utilização destes materiais se torna eficaz no processo de ensino e de aprendizagem matemática. Portanto, o uso de recursos didáticos pode possibilitar uma aprendizagem significativa para o estudante cuja inclusão se dá a partir do uso dessas ferramentas, viabilizando, também, a interação desse estudante com os seus pares e com o saber (FERNANDES, 2008).

\section{Referências}

BATISTA, J. O.; MIRANDA, P. B.; MOCROSKY, L. F. A utilização de recursos didáticos manipuláveis na Educação de alunos cegos ou com baixa visão no contexto matemático. Revista Teoria e Prática da Educação, [S. 1.], v. 19, n. 1, p. 113-122, 2016.

BRASIL. Lei ${ }^{\circ}$ 13.146, de julho de 2015. Institui a Lei Brasileira da Pessoa com Deficiência. Disponível em: http://www.planalto.gov.br/ccivil_03/_ato2015-2018/2015/lei/113146.htm. Acesso em: 05 jun. 2020.

BRITO, M. do C. Educação Matemática e a Deficiência Visual: Estudo de Caso em um Município da Região Metropolitana de Porto Alegre. 2007. Dissertação (Mestrado em Ensino de Ciências e Matemática) - Universidade Luterana do Brasil, Canoas, 2007. 
DECLARAÇÃO DE SALAMANCA: Sobre Princípios, Políticas e Práticas na Área das Necessidades Educativas Especiais, Salamanca-Espanha. 1994

FERNANDES, S. H. A. A. Das experiências sensoriais aos conhecimentos matemáticos: uma análise das práticas associadas ao ensino e aprendizagem de alunos cegos e com visão subnormal numa escola inclusiva. 2008. Tese (Doutorado em Educação Matemática) - Pontifícia Universidade Católica de São Paulo, São Paulo, 2008.

FERRONATO, R. A construção de Instrumento de Inclusão no Ensino de Matemática. 2002. Dissertação (Mestrado em Engenharia de Produção) - Universidade Federal de Santa Catarina, Florianópolis, 2002.

FURLAN, F. H. Conceitos Geométricos, Deslocamentos e Localização Espacial de Estudantes com Cegueira Congênita. 2016. Dissertação (Mestrado Profissional em Educação) - Universidade Federal do Paraná, Curitiba, 2016.

FRANCO, M. L.P. B. Análise de conteúdo. 3. ed. Brasília: Líber Livro, 2008.

LANDIM, E.; MAIA, L. S. L.; SOUSA, W. P. A. Representações sociais de Estudante Cego: aprender Matemática por professores de Matemática. Educação Matemática em Revista, Brasília, v. 22, n. 54, p. 67-80, 2017.

LIRIO, S. B. A tecnologia informática como auxílio no ensino de geometria para deficientes visuais. 2006. Dissertação (Mestrado em Educação Matemática) - Universidade Estadual Paulista "Júlio de Mesquita Filho", Rio Claro, 2006.

MARTINS, D. S.; GALIAZZI, M. C.; LIMA, C. A. Da Educação segregada à inclusiva: o que podemos aprender com a experiência de professores Cegos de Atendimento Educacional Especializado para o ensino de Matemática. VIDYA, Santa Maria, v. 37, n. 1, p. 177-197, 2017.

MELLO, E. M. O Professor, alunos Cegos e a Linguagem Matemática. Revista Paranaense de Educação Matemática, Campo Mourão, v. 2, n. 2, p. 132- 143, 2013.

MENDES, R. M.; MISKULIN, R. G. S. A análise de conteúdo como uma metodologia. Cadernos de Pesquisa, São Paulo, v. 47, n. 165, p. 1044-1066, Set. 2017. Disponível em:

http://www.scielo.br/scielo.php?script=sci_arttext\&pid=S010015742017000300013\&lng=en\&nrm=iso. Acesso em: 16 Mar. 2021.

MIRANDA, E. T. J. O aluno cego no contexto da inclusão escolar: desafios no processo de ensino e de aprendizagem de matemática. 2016. Dissertação (Mestrado em Educação para a Ciência) Universidade Estadual Paulista "Júlio de Mesquita Filho", Bauru, 2016.

NEVES, C. N.; MAIA, R. M. C. S. O uso de materiais adaptados para o ensino da matemática para estudantes com deficiência visual. BoEM, Joinville, v. 6, n. 11, p. 119-137, 2018.

PEREIRA, M. K. S. Ensino de geometria para alunos com deficiência visual: análise de uma proposta envolvendo a manipulação de materiais e a expressão oral e escrita. 2012. Dissertação (Mestrado Profissionalizante em Educação Matemática) - Universidade Federal de Ouro Preto, Ouro Preto, 2012.

SANTOS, F. L.; THIENGO, E. R.; Aprendizagem matemática de um estudante com baixa visão: uma experiência inclusiva fundamentada em Vygotsky, Leontiev e Galperin. Revista Paranaense de Educação Matemática, Campo Mourão, v. 5, n. 9, p. 104-120, 2016.

SILVA, V. C.; POSSAMAI, J. P.; REIS, D. S.; WINDISCH, T. D. Superando os obstáculos no 
desenvolvimento da inclusão em sala de aula com o auxílio de um projeto de extensão. Educação Matemática em Revista, Brasília, v. 24, n. 64, p. 183-194, set./dez. 2019.

SPLETT, E. S. Inclusão de alunos cegos em classes regulares e o processo ensino e aprendizagem da matemática. 2015. Dissertação (Mestrado em Educação Matemática e Ensino de Física) Universidade Federal de Santa Maria, Santa Maria, 2015.

ULIANA, M. R. Formação de professores de matemática, física e química na perspectiva da inclusão de estudantes com deficiência: análise de uma intervenção realizada em Rondônia. 2015. Tese (Doutorado em Educação em Ciências e Matemática) - Universidade Federal do Mato Grosso, Cuiabá, 2015.

VIGINHESKI, L. V. M. et al. Análise de produtos desenvolvidos no mestrado profissional na área de matemática: possibilidades de adaptações para o uso com estudantes cegos. Diálogo Educacional, Curitiba, v. 17, n. 51, p. 223-250, 2017.

VYGOTSKY, L. S. Obras Escogidas. Tomo V. Fundamentos de defectología. Madrid: Visor Distribuciones S.A., 1997.

Submetido em 09 de Junho de 2020. Aprovado em 23 de Outubro de 2020. 